Supporting Information

\title{
AuPd Nanoicosahedra: Atomic-Level Surface Modulation for Optimization of Electrocatalytic and Photocatalytic Energy
}

\section{Conversion}

Chen-Rui Kao, ${ }^{\Delta, \dagger}$ Yu-Cheng Huang,,${ }^{, \dagger}$ Biva Talukdar, ${ }^{\circ,+}$ Yu-Chun Chuang, ${ }^{\perp}$ Ying-Rui Lu, ${ }^{\perp}$ Hung-Min Lin, ${ }^{\wedge}$ Wu-Ching Chou," David A. Cullen, ${ }^{*, \# ~ C h u n g-L i ~ D o n g, ~}{ }^{*}, \|$ and Chun-Hong Kuo ${ }^{*, \Delta, \S}$

${ }^{\triangle}$ Institute of Chemistry, Academia Sinica, Taipei 11529, Taiwan

¿Department of Electrophysics, National Yang Ming Chiao Tung University, Hsinchu 30010, Taiwan ${ }^{\circ}$ Department of Applied Chemistry, National Yang Ming Chiao Tung University, Hsinchu 30010, Taiwan Sustainable Chemical Science and Technology, Taiwan International Graduate Program, Academia Sinica and National Yang Ming Chiao Tung University, Taipei 11529, Taiwan

${ }^{\perp}$ National Synchrotron Radiation Research Center, Hsinchu 30076, Taiwan

^Department of Chemistry, National Taiwan University, Taipei 10617, Taiwan

\#Center for Nanophase Materials Sciences, Oak Ridge National Laboratory, Oak Ridge, Tennessee 37831 6496, United States

"Department of Physics, Tamkang University, New Taipei 25137, Taiwan

§Institute of Materials Science and Engineering, National Central University, Taoyuan 32001, Taiwan

†.-R. K. and Y.-C. H. contributed equally to this work

Corresponding Author:

*(D.-A. Cullen) E-mail: cullenda@ornl.gov

*(C.-L. Dong) Email: cldong@mail.tku.edu.tw

*(C.-H. Kuo) E-mail: chunhong@gate.sinica.edu.tw 

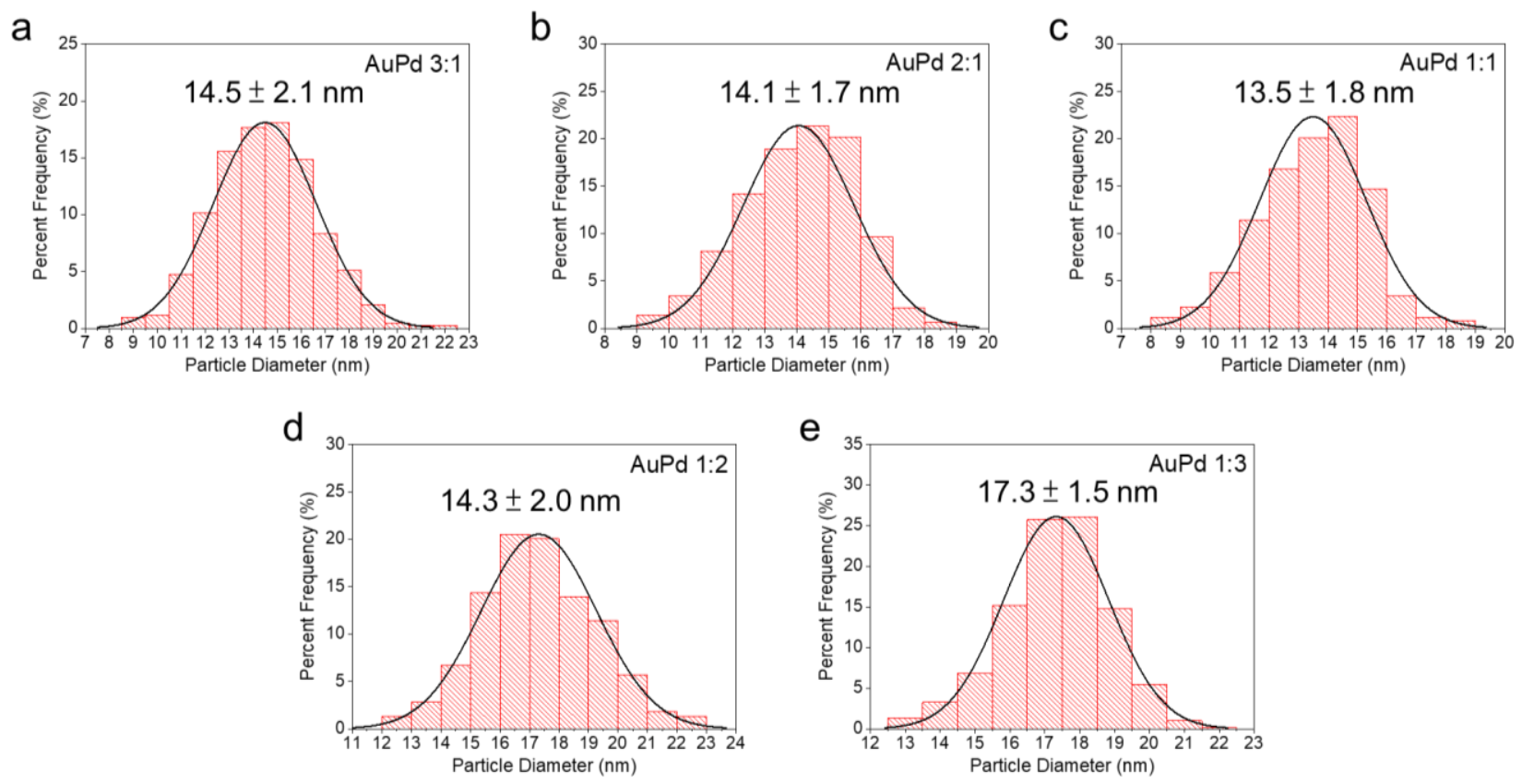

Figure S1. Size-distribution histograms of AuPd nanoicosahedra synthesized in different mixed ratio of $\left[\mathrm{HAuCl}_{4}\right] /\left[\mathrm{H}_{2} \mathrm{PdCl}_{4}\right]$.
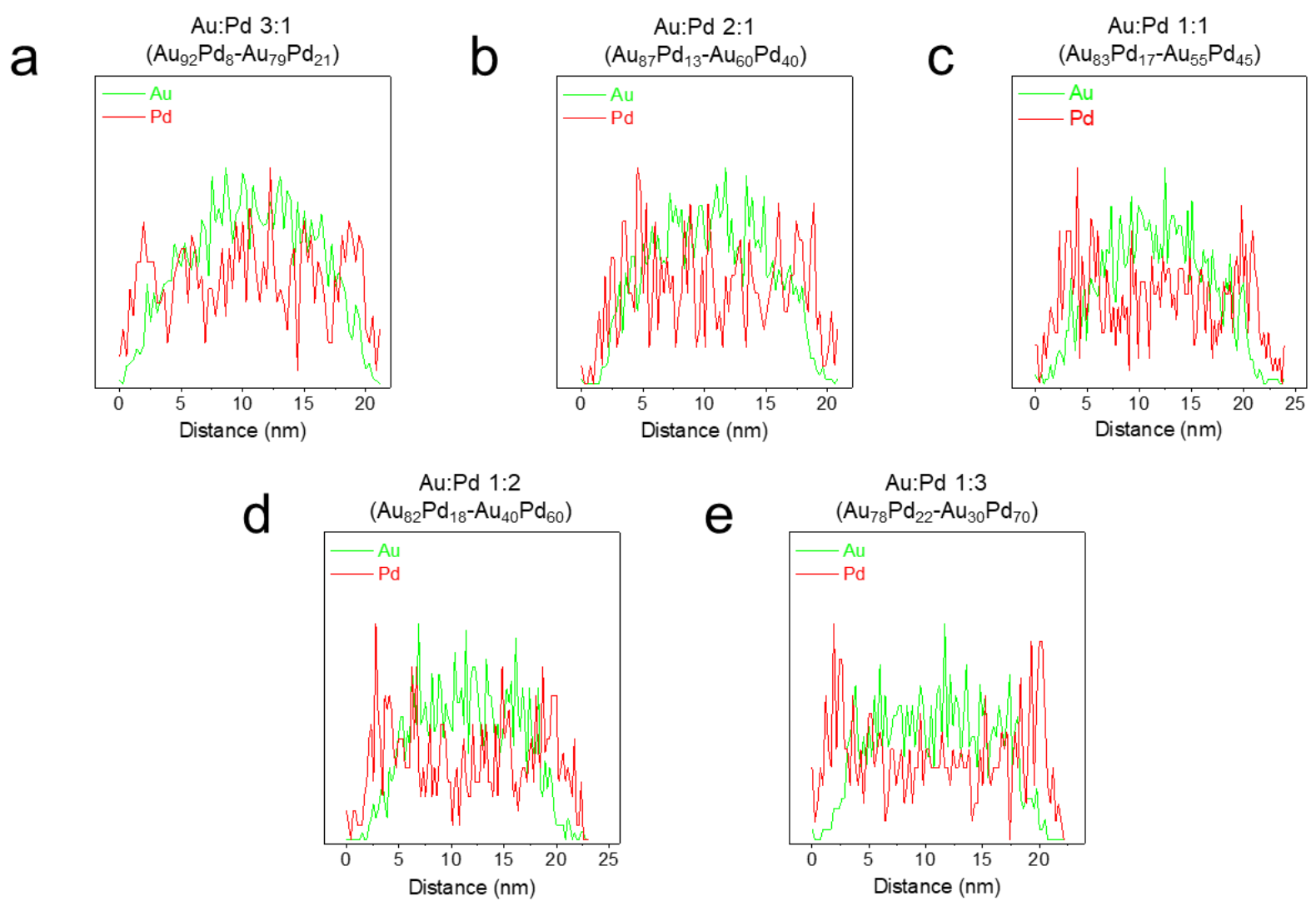

Figure S2. The EDS line-scan profiles of single nanoicosahedra corresponding with Figure 1k-o. 
Table S1. Summary of Au-Pd atomic percent ratios measured with different analytic techniques

\begin{tabular}{|c|ccccc|}
\multicolumn{2}{c}{ CTAB/CTAC } & $\mathbf{H A u C l}_{\mathbf{4}} / \mathbf{H}_{\mathbf{2}} \mathbf{P d C l}_{\mathbf{4}}$ & \multicolumn{4}{c|}{$\mathbf{A u} / \mathrm{Pd}$ Ratio } \\
\cline { 3 - 6 } Molar Ratio & Molar Ratio & XRD & ICP-OES & EDS Interior & EDS Surface \\
& $3: 1$ & $96: 4$ & $91: 9$ & $92: 8$ & $79: 21$ \\
\multirow{3}{*}{$25: 75$} & $2: 1$ & $91: 9$ & $80: 20$ & $87: 13$ & $60: 40$ \\
& $1: 1$ & $83: 17$ & $70: 30$ & $83: 17$ & $55: 45$ \\
& $1: 2$ & $77: 23$ & $61: 39$ & $82: 18$ & $40: 60$ \\
& $1: 3$ & $64: 36$ & $42: 58$ & $78: 22$ & $30: 70$ \\
\hline
\end{tabular}
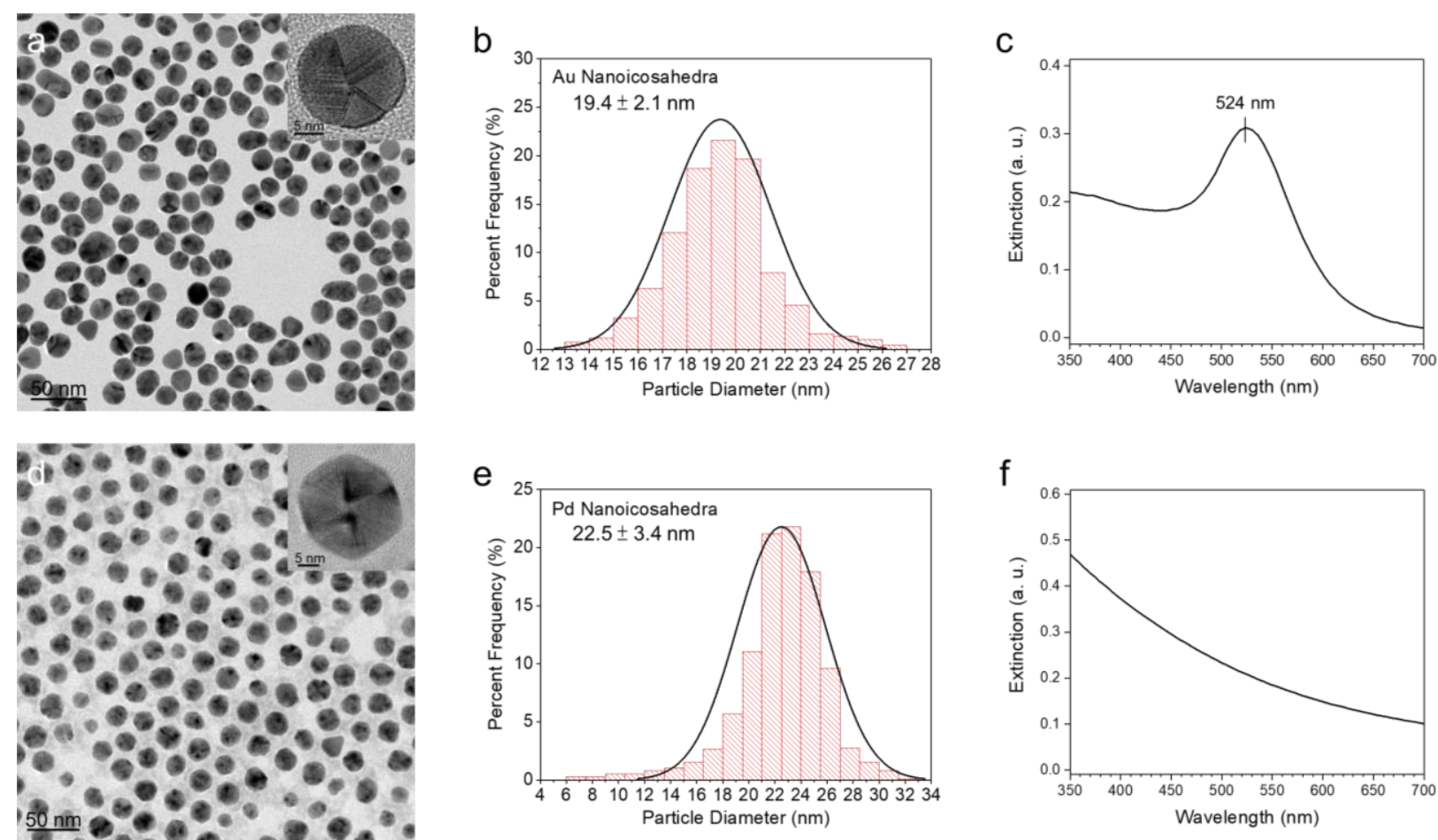

Figure S3. Bright-field TEM images, size-distribution histograms, and UV-vis spectra of (a-c) Au and (d-f) Pd nanoicosahedra. 
a

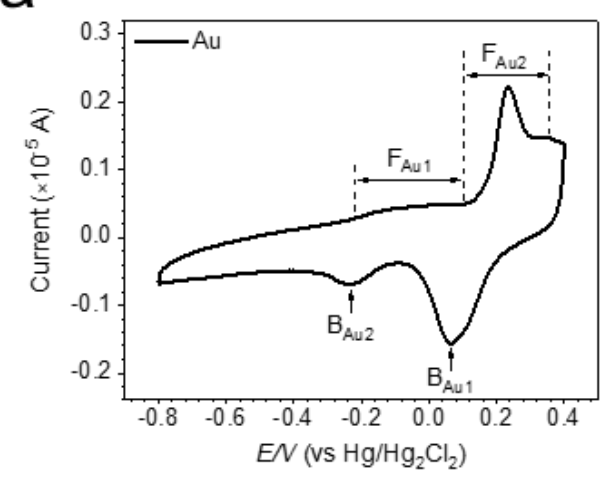

b

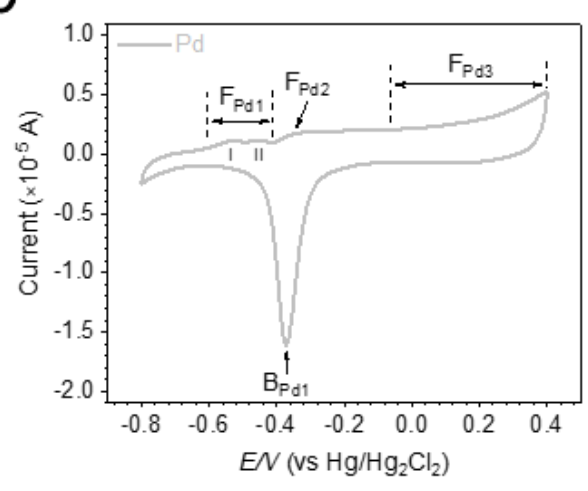

$\mathrm{F}_{\mathrm{Aul}} \mathrm{Au}+\mathrm{OH}^{-} \rightarrow \mathrm{Au}-\mathrm{OH}_{\mathrm{ads}}+\mathrm{e}^{-}$

$\mathrm{Au}+2 \mathrm{OH}^{-} \rightarrow \mathrm{Au}-\mathrm{O}+\mathrm{H}_{2} \mathrm{O}+\mathrm{e}^{-}$(monolayer)

$\mathrm{F}_{\mathrm{Au} 2} \quad \mathrm{Au}-\mathrm{OH}_{\mathrm{ads}}+\mathrm{OH}^{-} \rightarrow \mathrm{Au}-\mathrm{O}+\mathrm{H}_{2} \mathrm{O}+\mathrm{e}^{-}$

$\mathrm{Au}-\mathrm{OH}_{\mathrm{ads}}+\mathrm{Au}-\mathrm{OH}_{\mathrm{ads}} \rightarrow \mathrm{Au}-\mathrm{O}+\mathrm{H}_{2} \mathrm{O}+\mathrm{e}^{-}$

$\mathrm{B}_{\mathrm{Aul}} \mathrm{Au}-\mathrm{O}+\mathrm{H}_{2} \mathrm{O}+2 \mathrm{e}^{-} \rightarrow \mathrm{Au}+2 \mathrm{OH}^{-}$

$\mathrm{B}_{\mathrm{Au} 2}$

\begin{tabular}{|l|l|}
\hline$F_{\mathrm{Pd} 1}$ & $\mathrm{Pd}-\mathrm{H}_{\mathrm{abs} / \mathrm{ads}}+\mathrm{OH}^{-} \rightarrow \mathrm{Pd}+\mathrm{H}_{2} \mathrm{O}+\mathrm{e}^{-}(\mathrm{I}: \mathrm{abs} ; \mathrm{II}: \mathrm{ads})$ \\
\hline $\mathrm{F}_{\mathrm{Pd} 2}$ & $\mathrm{Pd}^{0}+\mathrm{OH}^{-} \rightarrow \mathrm{Pd}_{-} \mathrm{OH}_{\mathrm{ads}}+\mathrm{e}^{-}$ \\
\hline $\mathrm{F}_{\mathrm{Pd} 3}$ & $\begin{array}{l}\mathrm{Pd}-\mathrm{OH}_{\mathrm{ads}}+\mathrm{OH}^{-} \rightarrow \mathrm{Pd}-\mathrm{O}+\mathrm{H}_{2} \mathrm{O}+\mathrm{e}^{-} \\
\mathrm{Pd}^{-} \mathrm{OH}_{\mathrm{ads}}+\mathrm{Pd}-\mathrm{OH}_{\mathrm{ads}} \rightarrow \mathrm{Pd}-\mathrm{O}+\mathrm{H}_{2} \mathrm{O}+\mathrm{e}^{-}\end{array}$ \\
\hline $\mathrm{B}_{\mathrm{Pd} 1}$ & $\mathrm{Pd}-\mathrm{O}+\mathrm{H}_{2} \mathrm{O}+2 \mathrm{e}^{-} \rightarrow \mathrm{Pd}^{0}+2 \mathrm{OH}^{-}$ \\
\hline
\end{tabular}

Figure S4. CVs of (a) Au and (b) Pd nanoicosahedra scanned in a $0.5 \mathrm{M} \mathrm{KOH}$ electrolyte. All forward- and backward-scan peaks are assigned according to the chemical reactions in the tables. 
a

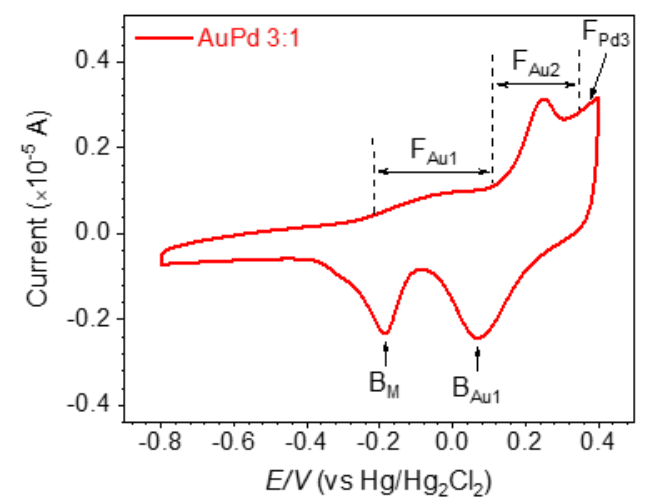

b

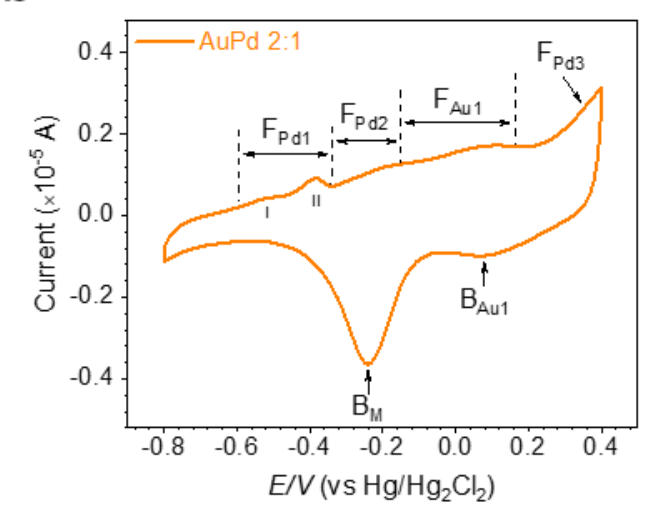

C

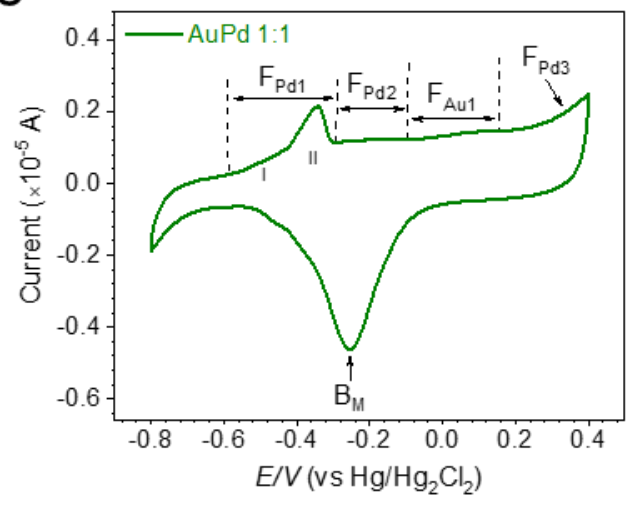

d

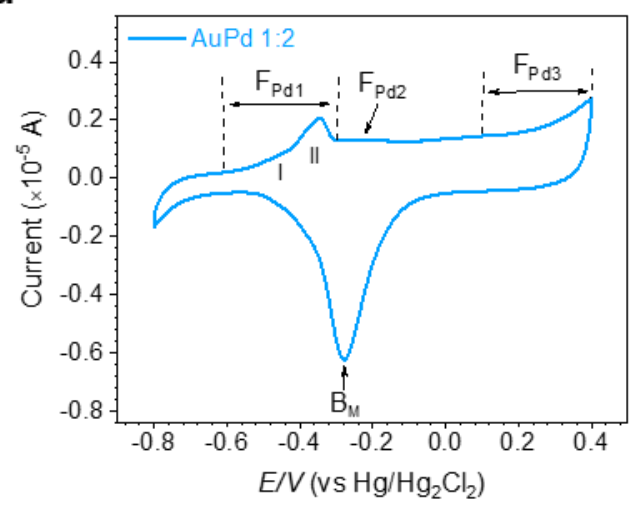

e

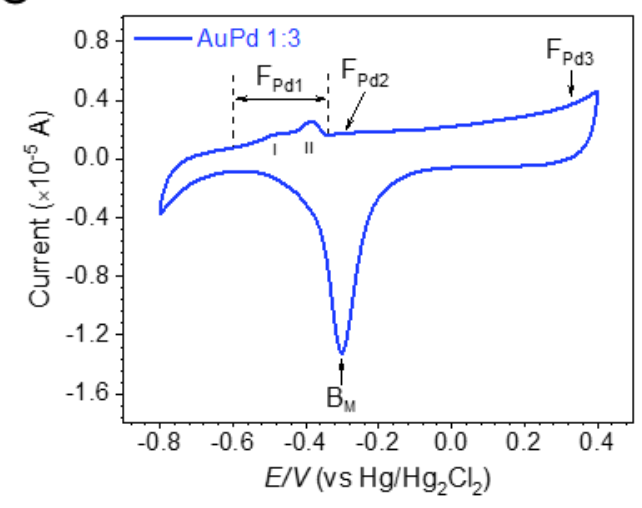

Figure S5. Blank-scan CVs of AuPd nanoicosahedra made in the $\mathrm{HAuCl}_{4} / \mathrm{H}_{2} \mathrm{PdCl}_{4}$ ratios of (a) 3:1, (b) 2:1, (c) 1:1, (d) 1:2, and (e) 1:3 in a $0.5 \mathrm{M} \mathrm{KOH}$ electrolyte. All forward- (F) and backward-scan (B) peaks are assigned to the corresponding reactions in the tables in Figure S3. 
a

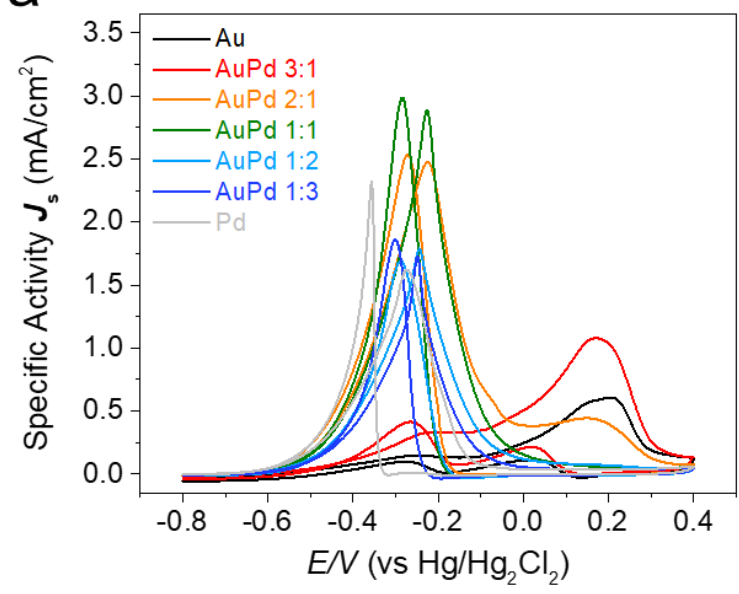

C

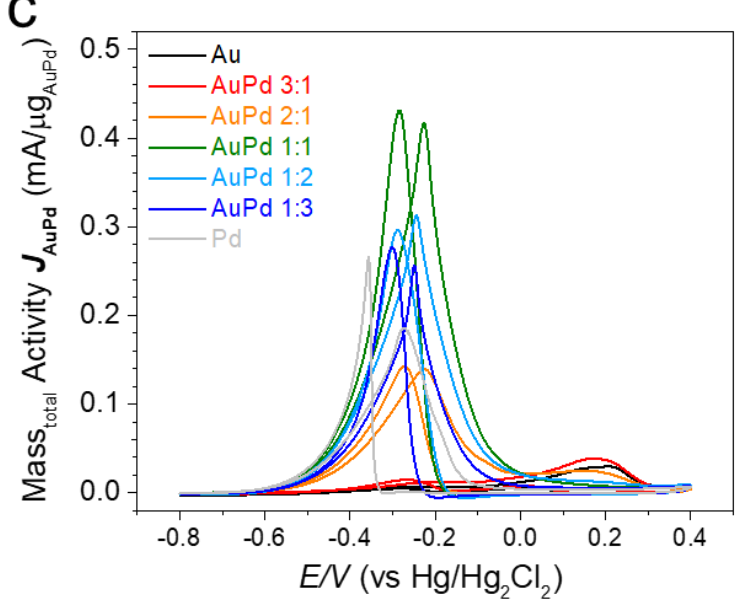

b

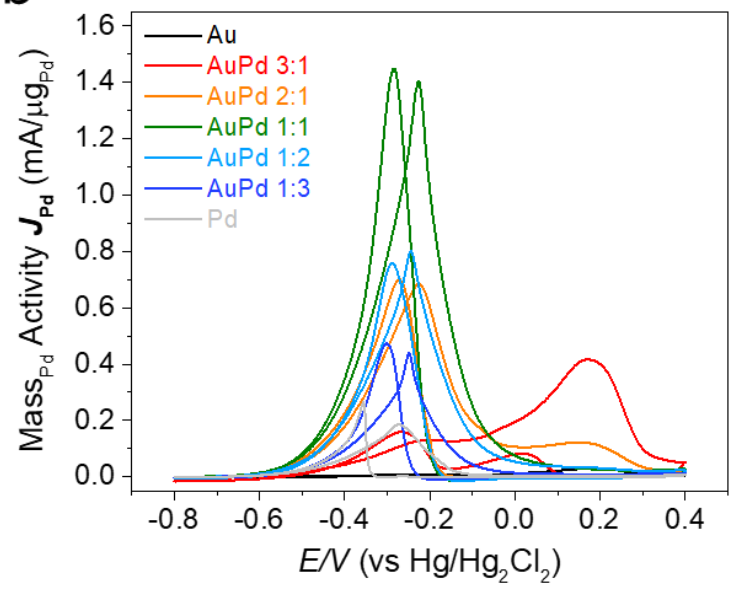

d

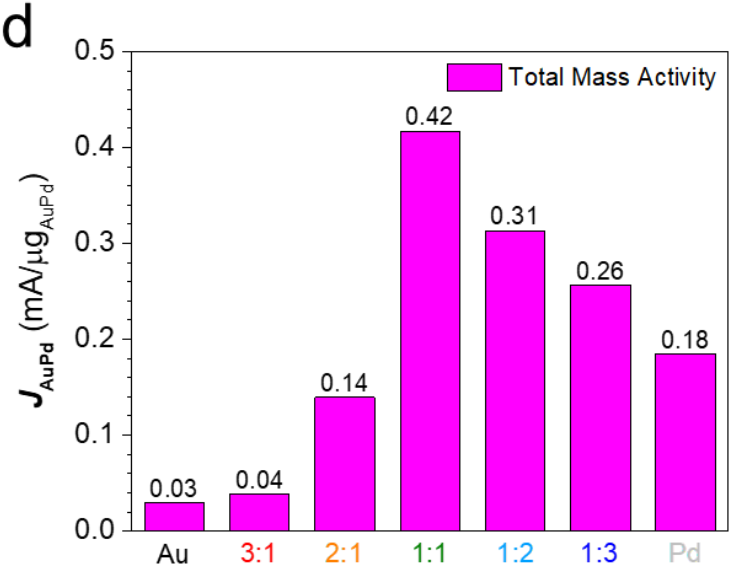

Figure S6. CVs of (a) specific, (b) Pd mass, and (c) total mass activities in electrochemical ethanol oxidation catalyzed by AuPd, $\mathrm{Au}$, and Pd nanoicosahedra. (d) Collection of total mass activities for the same group of samples. 

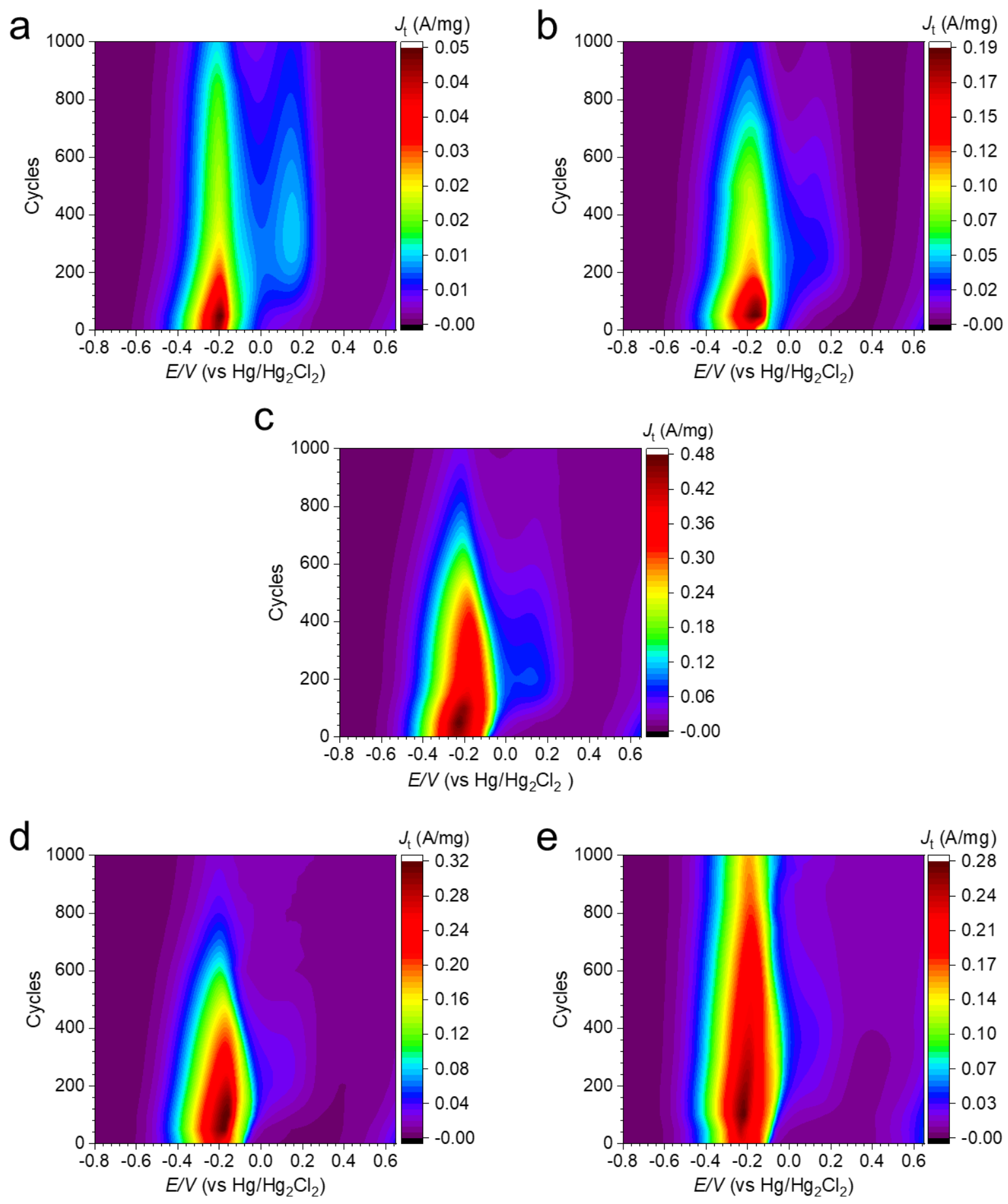

Figure S7. 2D contour of Bode plots of total mass activities $(J \mathrm{t})$ in electrochemical ethanol oxidation for 1000 cycles by AuPd nanoicosahedra synthesized in the $\mathrm{HAuCl}_{4} / \mathrm{H}_{2} \mathrm{PdCl}_{4}$ ratios of (a) 3:1, (b) 2:1, (c) 1:1, (d) 1:2, and (e) 1:3. 


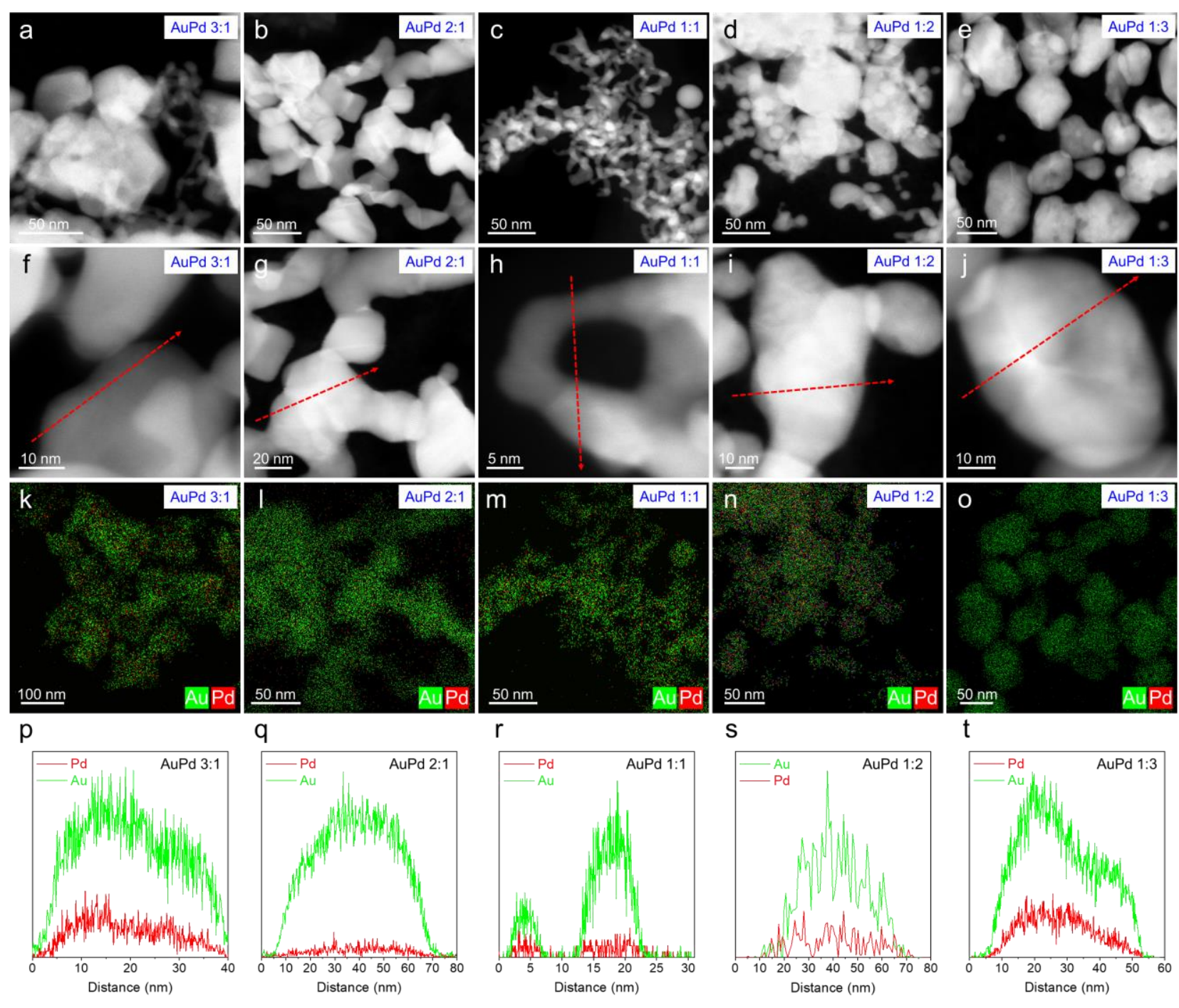

Figure S8. (a-j) HAADF-STEM images, (k-o) EDS maps, and (p-t) EDS line-scan profiles of AuPd nanoicosahedra after 1000-cycle durability test in EOR. 

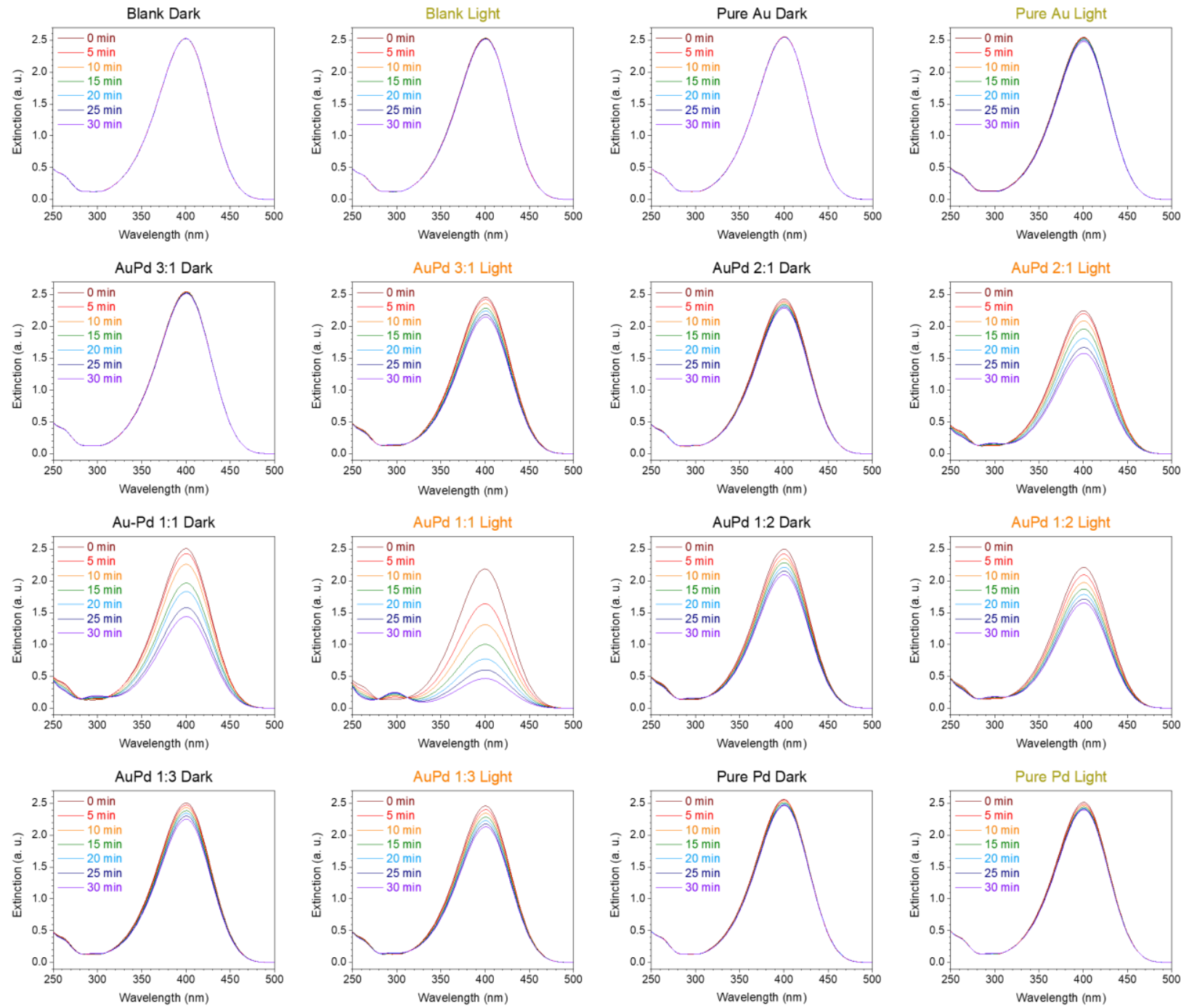

Figure S9. UV-vis spectra of catalytic 4-nitrophenol reduction catalyzed by no catalyst (blank), pure $\mathrm{Au}$, pure $\mathrm{Pd}$, and $\mathrm{AuPd}$ nanoicosahedra. 


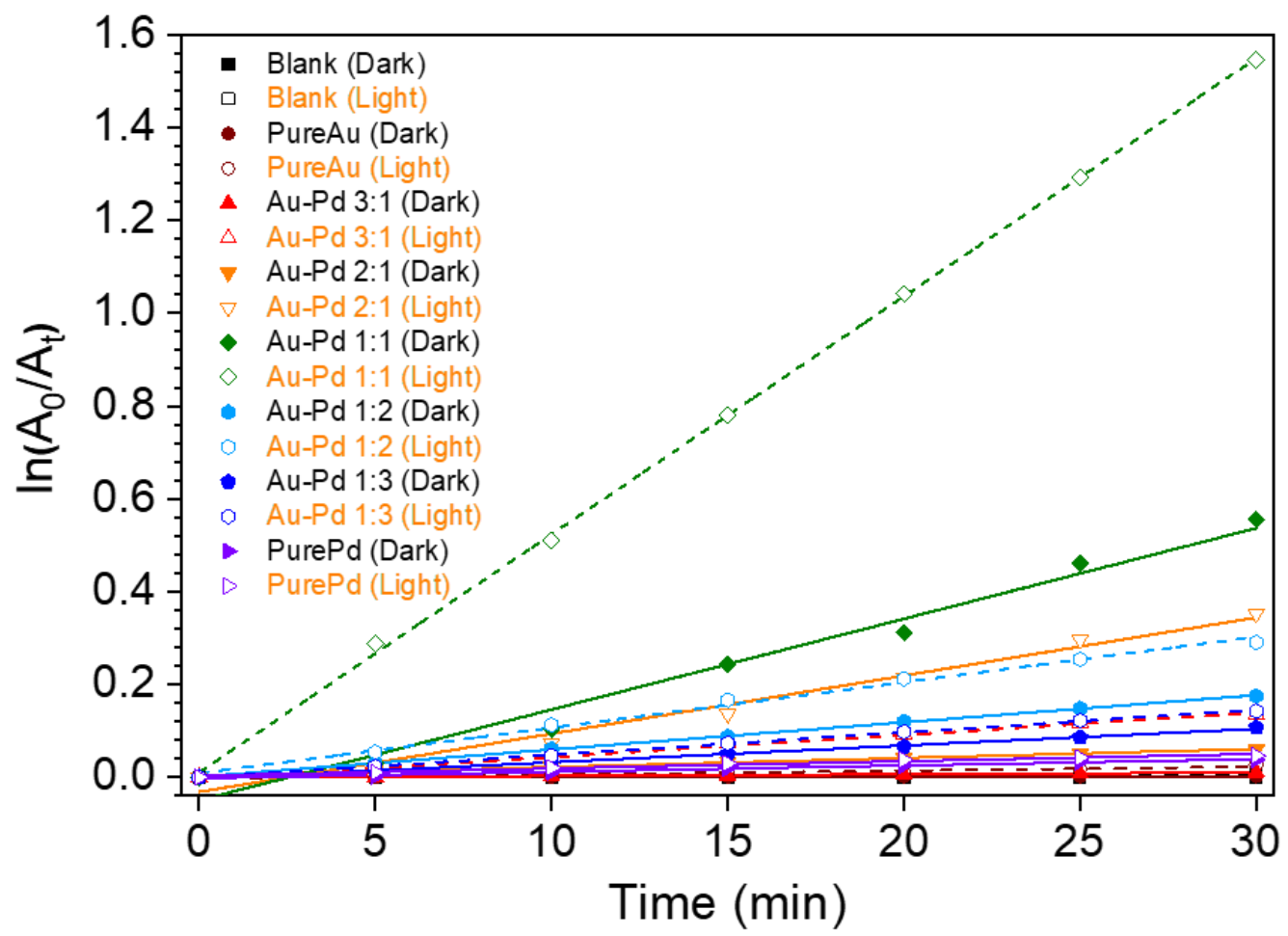

Figure S10. The plot of $\ln \left(\mathrm{A}_{0} / \mathrm{A}_{\mathrm{t}}\right)$ vs time from the reaction of 4-nitrophenol reduction catalyzed by $\mathrm{AuPd}, \mathrm{Au}$, and Pd nanoicosahedra. The solid lines indicate the reactions run in dark and the dash lines represent those carried out under illumination of visible light.

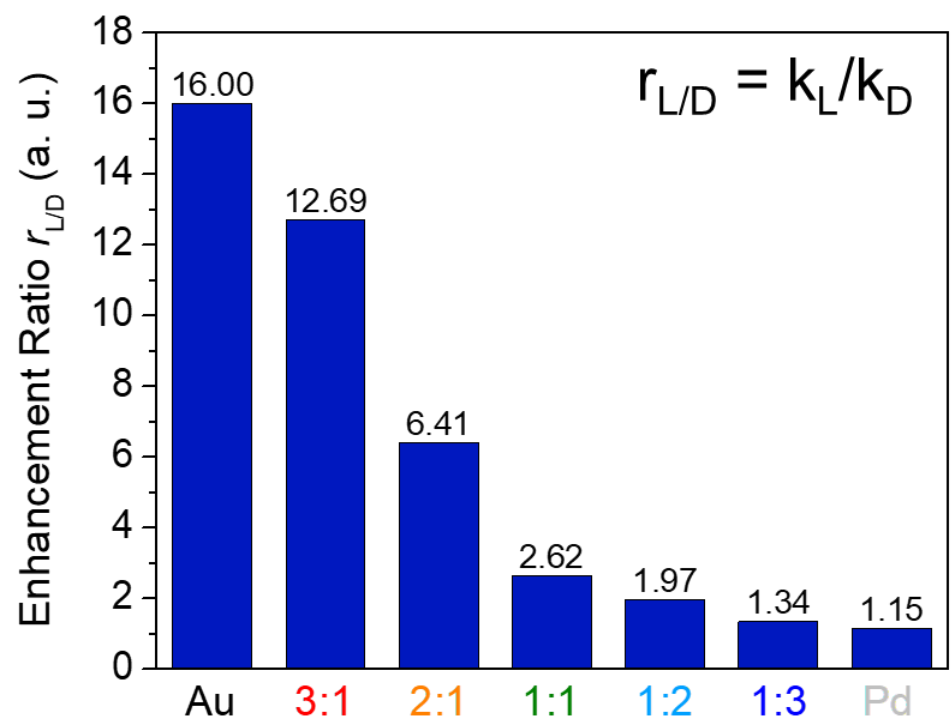

Figure S11. Photo-enhancement ratios of $\mathrm{Au}, \mathrm{Pd}$ and $\mathrm{AuPd}$ nanoicosahedra obtained from $\mathrm{k}_{\mathrm{L}} / \mathrm{k}_{\mathrm{D}}$, where $\mathrm{k}_{\mathrm{L}}$ denotes the reaction rate under light illumination and $\mathrm{k}_{\mathrm{D}}$ in dark. 


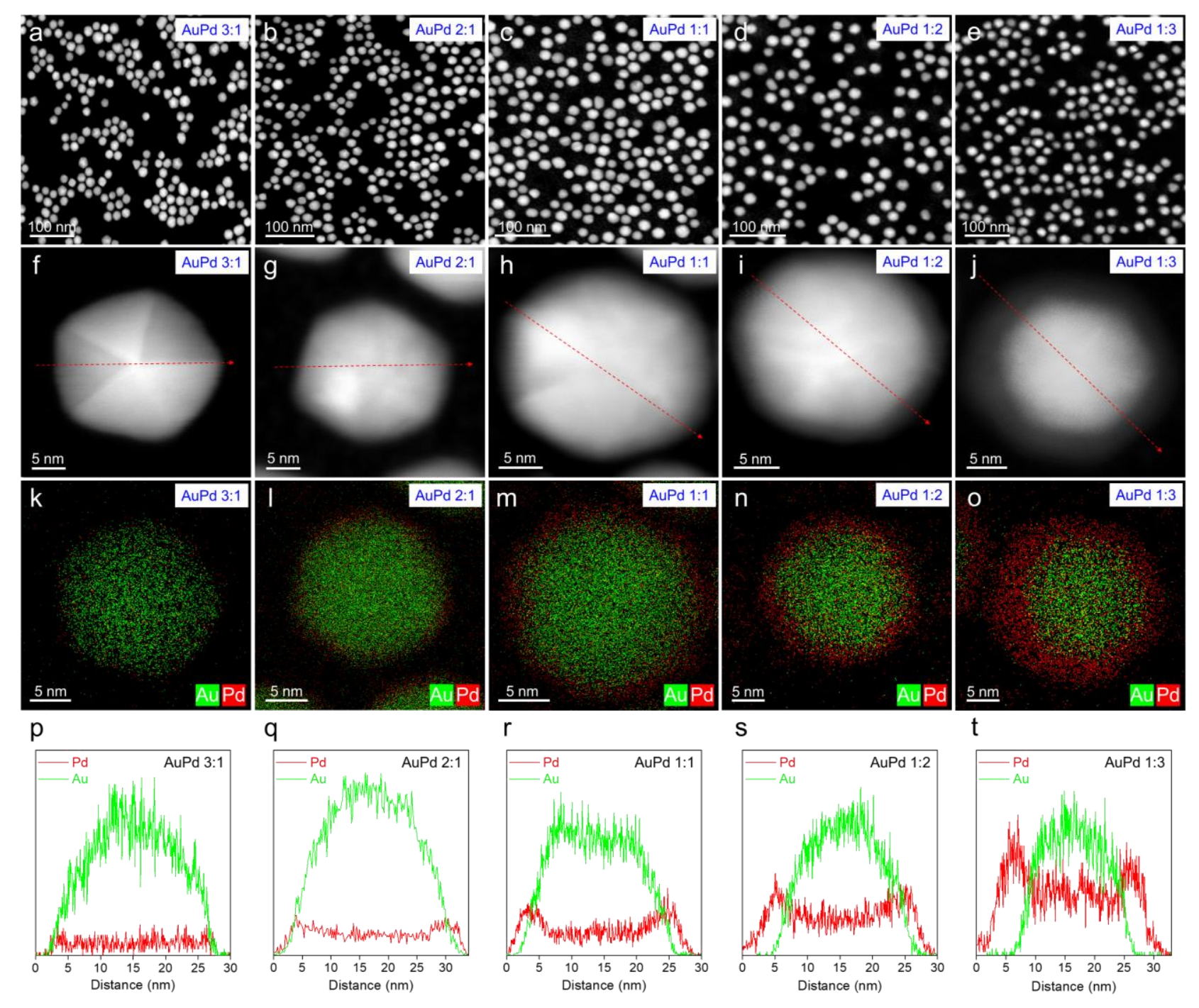

Figure S12. (a-j) HAADF-STEM images, (k-o) EDS maps, and (p-t) EDS line-scan profiles of AuPd nanoicosahedra after one-hour 4-NP reduction reaction in dark. 


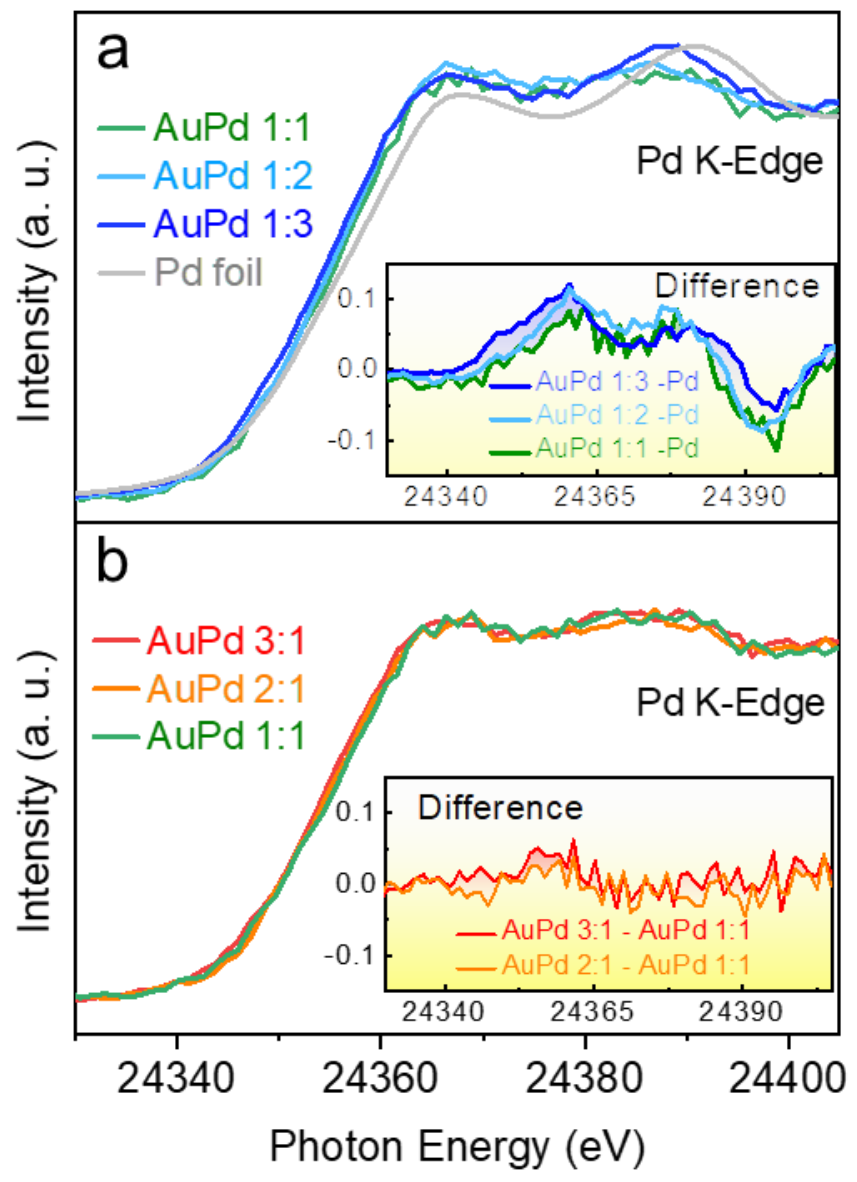

Figure S13. (a) Pd K-edges of AuPd nanoicosahedra ( $\mathrm{Au}: \mathrm{Pd}=1: 3,1: 2$ and 1:1) and Pd foil. The inset shows the derived spectra obtained by subtracting the spectrum of Pd foil from those of AuPd nanoicosahedra. (b) Pd K-edges of AuPd nanoicosahedrals (Au:Pd =1:1, 2:1 and 3:1). The inset shows the derived spectra obtained by subtracting the spectrum of $\operatorname{AuPd}(1: 1)$ from those of $\operatorname{AuPd}(3: 1)$ and $\operatorname{AuPd}(2: 1)$, respectively. 

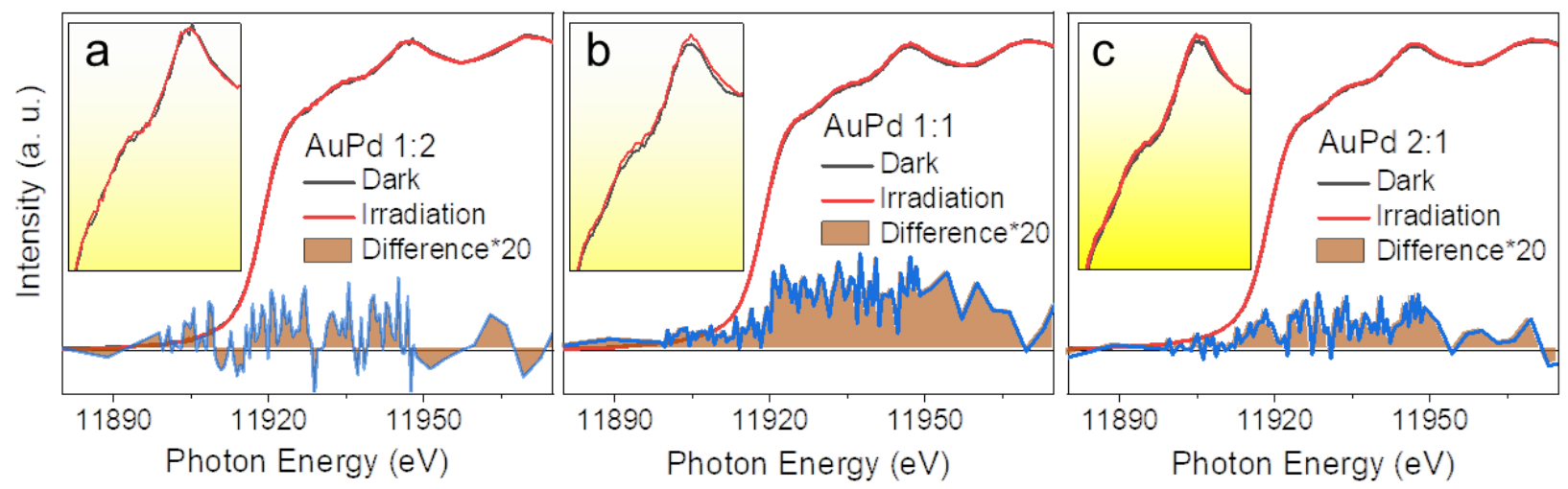

Figure S14. $\mathrm{Au} \mathrm{L}_{3}$-edges of AuPd nanoicosahedra in dark and under solar-light irradiation (1.5 AM). Spectral differences are magnified 20 times as shown beneath the edge curves. Insets magnifies the spectral alternation by irradiation. 